\title{
Sentence writing in the cognitive assessment of the elderly
}

\author{
ROBert Howard, Lecturer, Section of Old Age Psychiatry, Institute of Psychiatry, \\ London SE5 8AF; and MARTIN ORRELL, Senior Registrar, Bethlem and \\ Maudsley Hospitals, London SE5 8AZ
}

\section{The study}

Testing the ability to write a simple sentence has long formed part of the clinical assessment of the cognitive state in the elderly, and has even been incorporated into standard brief cognitive tests (Folstein et al, 1975). Writing a sentence tests a number of faculties including language skills and praxis. As part of a comparative study of four tests of cognitive function-the Felix Post Unit (Institute of Psychiatry, 1987), Mini Mental State Examination (Folstein et al, 1975), Abbreviated Mental Test (Qureshi \& Hodkinson, 1974) and Medical Research Council (MRC, 1987)-sentences written by 158 elderly newly admitted psychiatric patients, as requested in the Mini Mental State, were collected. Our aims were to assess the value of sentence-writing in discriminating between dementia and depression, and to compare the style and content of what was written. Would the material chosen by the patients for their sentences be associated with their diagnoses? In particular, would depressives write miserable sentences and the demented be more likely to write nonsense?

The consultant discharge diagnosis for each patient was recorded and the patients divided into those with an organic disorder and those with a functional illness (e.g. depression or late paraphrenia). The sentences were examined by a single rater (RH) for completeness, length and content.

\section{Findings}

Some of the patients were unable to write anything at all, or could only manage a single word. Such an effort was classed as "No sentence". A number of nonsense sentences were produced, for example, "War makes us chang ven to", while other patients wrote only their names or addresses. Of the organic group, $33 \%$ produced no sentence at all compared with $15 \%$ of the functional patients. A correct sentence was written by $54 \%$ of the organic and $75 \%$ of the functional patients. Nonsense sentences or names and addresses were written by $13 \%$ of the organic group and $10 \%$ of the functional group.

The length of sentence, whether nonsense or correct, was recorded in terms of the number of words involved; $26 \%$ of the organic and $34 \%$ of the functional patients wrote four or fewer words. Sentences containing between five and seven words were produced by $56 \%$ of the organic group and $53 \%$ of the functional group. Longer sentences, containing eight or more words, were written by $18 \%$ of the organic and $13 \%$ of the functional patients.

Finally, the content of those sentences that made some sort of sense was assessed. The completed sentences fell into five main groups. Some took the form of a post-card type message, for example, "Dear Lil, just a line home to you" (10\% of organic and $13 \%$ of functional patients). A second group were selfreferential, for example, "I wish I was not here" or "I am happy" (33\% of organic and $36 \%$ of functional patients). The third group had a religious or proverbial content, for example, "God be merciful" or "She who does does well" ( $21 \%$ of organic and $6 \%$ of functional cases). A fourth group took the form of a writing exercise such as "The cat sat on the mat" ( $19 \%$ of organic and $39 \%$ of functional cases). The final group were all examiner-related, for example, "You are a nice doctor" or "You are visiting me this afternoon" (16\% or organic and $6 \%$ of functional cases).

\section{Comment}

Earlier workers examining factors affecting errors made during the "Write a sentence" component of the Mini-Mental State Examination have reported low educational status (Escobar et al, 1986, O'Connor et al, 1989) and lower social class (O'Connor et al, 1989) to be significantly associated with impaired ability on this item. From this descriptive study it is apparent that a request to write a complete sentence, if made of an elderly person undergoing cognitive assessment, results in the production of a wide range of efforts in terms of their quality, length and content. Do the differences in sentence construction help to differentiate between patients with dementia and those with a functional illness such as depression? The answer to this question seems to be yes. Patients who failed to produce a correct sentence were more likely to be demented $\chi^{2}=$ 7.92; $P<0.05$ )) than depressed. In the differentiation 
of cases of dementia from those of depression, production of a complete sentence had a sensitivity of 0.75 and a specificity of 0.47 . If a patient fails to produce a correct sentence, there is thus a high likelihood of dementia. Such a failure, however, is not useful for screening purposes, since the majority of dementia patients may still be able to produce a sentence.

There were no differences in the length of sentences produced by the two groups of patients.

As to the chosen content of the sentences, demented patients were more likely to write about the examining doctor, or use a religious or proverbial theme. Perhaps surprisingly, patients with functional illness predominated in the use of copy-book type writing exercises, even though the demented patients might have been expected to favour such early-learnt and more concrete material.

We conclude that, while an error on the "Write a sentence" component of the Mini Mental State Examination is highly suggestive of a diagnosis of dementia, such a mistake is not a good screen for dementia in a mixed psychogeriatric population.
Similarly, written sentence length and content are not indicators of diagnosis.

\section{References}

Escobar, J. I., Burnham, A., Karno, M. et al (1986) Uses of the Mini-Mental State Examination in a community population of mixed ethnicity. Journal of Nervous and Mental Disease, 174, 607-614.

Folstein, M. F., Folstein, S. E. \& McHugh, P. R. (1975) Mini Mental State: A practical method for grading the cognitive state of patients for the clinician. Journal of Psychiatric Research, 12, 189-198.

INSTITUTE OF PSYCHIATRY (1987). Notes on Eliciting and Recording Clinical Information. Oxford: Oxford University Press.

MEDICAL RESEARCH COUNCIL (1987) Report from the MRC Alzheimer's Disease Workshop. London. MRC.

O'Conner, D. W., Pollitt, P. A., Treasure, F. P. et al (1989) The influence of education, social class and sex on Mini-Mental State scores. Psychological Medicine, 19, 771-776.

QURESHI, K. N. \& Hodkinson, H. M. (1974) Evaluation of a ten question mental test in the institutionalised elderly. Age and Ageing, 3, 152-157.

\section{Erratum}

Relocation of long-stay general psychiatric inpatients. By L.S. Chong and P.M. Abbott (Psychiatric Bulletin, January 1992, 16, 22). The fifth paragraph reads: "The rehab. scores showed a statistically global improvement ( $P$ values from 0.25 to 0.001$)$ ". The latter phrase should read $P$ values from 0.025 to 0.001 .

\section{Trainee Editorship}

A new scheme offering SRs training in scientific editorial work and medical writing is now available through The British Journal of Psychiatry. The successful applicant will be able to spend one special interest session a week attached to the BJP for six months. It is planned that he/she will be attached to one or more experienced Journal editors and will be given papers to assess under supervision. The trainee will also follow the progress of accepted papers through the editing process to eventual publication. The trainee will have short attachments to other sections of the Journal - the Book Reviews and Correspondence columns - and may also have the opportunity to assess articles submitted to the Bulletin under supervision. In addition, the successful applicant will be encouraged to develop his/her writing skills and it is hoped he/she may write an article or series of articles for the Bulletin as well as covering several meetings over the year. 